M+A Revista Electrónica de Medioambiente

ISSN-e: $1886-3329$

http://dx.doi.org/10.5209/MARE.57984

\title{
Justificación y conveniencia de la responsabilidad penal de las personas jurídicas en Chile, en delitos contra el Medio Ambiente
}

\author{
Macarena Vivanco del Solar ${ }^{1}$ \\ Recibido: 13 de septiembre del 2017/ Enviado a evaluar: 19 de septiembre del 2017/ Aceptado: 10 de noviembre del 2017
}

Resumen. El artículo aborda la revisión del principio "societas delinquere non potest", así como a los problemas pragmáticos y dogmáticos asociados a la responsabilidad penal de las personas jurídicas, particularmente, en relación con los denominados delitos ecológicos, con el propósito de dilucidar la conveniencia de su establecimiento en Chile. Para tales efectos, se revisa el origen de la intervención penal en materia de medio ambiente, así como la estrecha relación que, en esta materia, existe entre el Derecho Penal y el Derecho Administrativo. Del mismo modo, se incluye el estudio de las diversas posturas formuladas en el debate acerca de la posibilidad de sancionar criminalmente a los entes colectivos, de los distintos modelos de imputación propuestos por la doctrina y de los sistemas sancionatorios imperantes en España y Chile. Finalmente se realiza un breve análisis del sistema administrativo sancionador que impera en Chile, en materia medioambiental.

Palabras clave: Responsabilidad penal de las personas jurídicas; delito ecológico; Derecho Penal; Derecho Administrativo.

\section{[en] Justification and convenience of the criminal responsibility of legal entities in Chile, in crimes against the Environment}

Abstract. The article refers to the revision of the principle "societas delinquere non potest", as well as to the pragmatic and dogmatic problems associated with the criminal responsibility of companies, particularly in relation to the so-called ecological crimes, with the purpose of elucidating the convenience of its establishment in Chile. For these purposes, the origin of the criminal intervention in environmental matters is reviewed, as well as the close relationship that, in this matter, exists between Criminal Law and Administrative Law. Likewise, the investigation includes the study of the different positions formulated in the debate about the possibility of criminally sanctioning the collective entities, the different models of imputation proposed by the doctrine and the sanctioning systems prevailing in Spain and Chile. Finally, a brief analysis of the sanctioning administrative system that exists in Chile, in environmental matters, is carried out.

Key words: Corporate criminal responsibility; ecological crime; Criminal Law; Administrative Law.

${ }^{1}$ Universidad Santiago de Chile (Chile).

E-mail: mvivanco@alcainoabogados.cl 


\section{[fr] Justification et commodité de la responsabilité pénale des personnes morales au Chili, dans les crimes contre l'environnement}

Résumé. L'article traite de l'examen du principe «societas delinquere non potest», ainsi que des problèmes pragmatiques et dogmatiques associés à la responsabilité pénale des personnes morales, en particulier en ce qui concerne les infractions environnementales soi-disant, afin d'élucider la pertinence de sa création au Chili. A cet effet, l'origine de la participation criminelle en matière d'environnement et la relation étroite dans ce domaine entre le droit pénal et le droit administratif est passée en revue. De même, l'étude des différentes positions exprimées dans le débat sur la possibilité de sanctionner pénalement ces entités collectives, les différents modèles proposés par la doctrine de l'imputation et les systèmes punitifs en vigueur en Espagne et au Chili est inclus. Enfin, une brève analyse du système de sanction administrative qui prévaut au Chili, en matière d'environnement.

Mots clés: Responsabilité pénale des personnes morales; crime écologique; Droit pénal; Droit administratif.

Cómo citar. Vivanco del Solar, M. (2017): Justificación y conveniencia de la responsabilidad penal de las personas jurídicas en Chile, delitos contra el Medio Ambiente. $M+A$ Revista Electrónica de Medioambiente, 18 (2), 197-224.

Sumario. 1. Introducción. 1.1. Estado de la cuestión en Chile. 2. El origen de la protección penal del Medio Ambiente y principales críticas. 3. Principio de intervención mínima (ultima ratio). 4. Principio non bis in idem. 5. Responsabilidad penal de las personas jurídicas. 6. Cuestionamientos dogmáticos. 7. Modelos de imputación. 7.1. Modelo de responsabilidad por atribución (Modelo vicarial). 7.2. Modelo de autorresponsabilidad. 7.3. Modelo de imputación chileno y español. 8. Legislación del Medio Ambiente en Chile. 8.1. Delitos contra el meido ambiente y recursos naturales. Marco constitucional y situación actual. 8.2. Ley de base del medio ambiente. 8.3. Principales funciones de la Superintendencia de Medio Ambiente. 9. Conclusiones 10. Bibliografía.

\section{Introducción}

La idea de acudir al Derecho Penal para hacer frente a los nuevos riesgos, propios de la sociedad en que vivimos, se funda en el entendimiento que el desarrollo científico y tecnológico, así como el afianzamiento de los medios de comunicación y la integración de los mercados, dan origen a nuevas formas de criminalidad. ${ }^{2}$ Sin embargo, la protección penal del medio ambiente, clamada desde sectores muy diversos, continúa provocando polémicas doctrinarias tanto en el plano políticocriminal como dogmático. La aplicación de las herramientas clásicas a los tipos penales que protegen los nuevos bienes jurídicos colectivos - tipos de peligro, más que de lesión, que operan en áreas intensamente reguladas por el Derecho

${ }^{2}$ PARIONA ARANA, R. Aproximaciones al Derecho penal económico. Del nacimiento de un nuevo Derecho penal a una aproximación crítica, en L. Reyna Alfaro (coord.), Nuevas tendencias del Derecho penal económico y de la empresa. Lima, 2005. Ara Editores. Pp. 257279 . 
Administrativo y en las que intervienen regularmente personas jurídicas- se ha enfrentado a dificultades mayores ${ }^{3}$ que no han logrado disiparse con el transcurso del tiempo. En efecto, en las últimas décadas se ha generado un intenso e interesante debate doctrinario en relación con la expansión o hipertrofia del Derecho Penal hacia disciplinas no cubiertas por el Derecho Penal tradicional, en las que se protegen bienes jurídicos supraindividuales, mediante la utilización de delitos de peligro y de leyes penales en blanco, como ocurre - precisamente- con el Derecho Penal del medio ambiente.

Por otra parte y a propósito de las particularidades propias de la sociedad moderna, que se caracteriza por un tráfico complejo de relaciones comerciales entre empresas, ya comenzado el siglo XXI, se sigue debatiendo sobre de la posibilidad de revisión del principio "societas delinquere non potest" asentado en nuestra tradición jurídica desde el siglo XVIII. ${ }^{4}$ Desde entonces y hasta la actualidad existen desacuerdos y discusiones acerca de si las personas jurídicas pueden o no, desde la perspectiva doctrinaria, ser responsables penalmente.

Quienes defienden la responsabilidad penal de las personas jurídicas sostienen que muchos delitos son cometidos en el seno de las empresas o bajo su amparo, en beneficio o provecho de estas últimas y agregan, especialmente en materias medioambientales, que dichas entidades son quienes realizan conductas ilícitas con mayor frecuencia y contenido de dañosidad, denunciando -al mismo tiempo- la insuficiencia del derecho administrativo sancionador para enfrentar esta clase de conductas. Sin embargo, en nuestra opinión, lo fundamental no es el establecimiento dogmático de la responsabilidad penal de las empresas (como corolario del aumento de la criminalidad empresarial en materia medioambiental), sino que lo relevante $-\mathrm{y}$ de mayor utilidad- es buscar la mejor estrategia para prevenir eficazmente las conductas ilícitas que atentan contra el medio ambiente y que involucran a las personas jurídicas. En otras palabras, a pesar de la razonabilidad que existe tras lo expuesto por quienes abogan por la responsabilidad penal de las personas jurídicas como "el" mecanismo "suficiente" para combatir (ya sea previniendo o persiguiendo) la realización de hechos ilícitos, este criterio no puede ni debe emplearse con prescindencia de la realidad fáctica y legislativa del territorio específico en el que se aplicará (en este caso, Chile), pues puede darse que -en el caso concreto- no sea la única ni la mejor estrategia para resolver la incuestionable degradación del medio ambiente que enfrentamos en la actualidad.

3 DE LA CUESTA ARZAMENDI, J. Cuestiones dogmáticas relativas al delito de contaminación ambiental. Revista Penal, 4, 1999. Pp. 30-41.

${ }^{4}$ Desde el siglo XIV al XVIII las personas jurídicas fueron responsables penalmente. 


\subsection{Estado de la cuestión en Chile}

En 2009, bajo el pretexto de constituir un requisito para el ingreso de Chile a la OCDE y sin mayores discusiones ni debates acerca de su conveniencia ni justificación, se publicó y entró en vigencia la Ley $\mathrm{N}^{\mathrm{o}} 20.393$ que establece la responsabilidad penal de las personas jurídicas en los delitos de lavado de activos, cohecho, terrorismo y, desde 2016, la receptación

Por otra parte, y a pesar que en Chile no existe una regulación armónica, sistemática y suficiente de la criminología medioambiental, sino que la legislación penal en esta materia se encuentra en un estado de desarrollo de "prescindencia", en que la regulación de conductas atentatorias está dispersa en el Código Penal y en diversas leyes especiales, en las que no han sido establecidas directa e independientemente con ese propósito, sino que con la finalidad de proteger otros bienes, pero que -al momento de la codificación o al de dictarse las leyes especiales- se consideraron como dignos de una protección penal. A pesar de ello, existe un relativo consenso en cuanto a la necesidad de su incorporación en la legislación nacional, aunque dicha circunstancia no se ha manifestado en un debate serio y profundo, como el que se requiere.

Finalmente cabe señalar que, a partir de 2010, se ha instaurado en Chile la nueva institucionalidad ambiental que, entre otros elementos, considera una Superintendencia de Medio Ambiente, cuyas facultades fiscalizadoras y sancionatorias son amplias y, al mismo tiempo, muy severas para las empresas, circunstancia que -en principiopermite suponer grandes avances en la protección y conservación del medio ambiente.

\section{El origen de la protección penal del Medio Ambiente y principales críticas}

En la doctrina penal moderna existe una referencia bastante habitual al concepto de sociedad postindustrial ${ }^{5}$ o sociedad del riesgo ${ }^{6}$, para justificar la expansión del

\footnotetext{
${ }^{5}$ Según la doctrina, la capacidad de impacto ambiental de los grupos humanos aumentó tremendamente desde la Revolución Industrial y muy especialmente durante el período llamado «fordista» del capitalismo (a partir de 1930-1950). Desde mediados de siglo, la expansión del sistema socioeconómico se ha acelerado hasta convertirse en un proceso prácticamente fuera de control, circunstancia que originaría el abuso de los recursos naturales y ocasionaría desastres ecológicos. VERCHER NOGUERA, A. Evolución jurisprudencial del delito contra el medio ambiente. Revista Jurídica de Castilla y León. No 1, septiembre de 2003. Pp. 226.

${ }^{6}$ Concepto desarrollado por el sociólogo alemán ULRICH BECK en 1986 en su obra La sociedad del riesgo. Hacia una nueva modernidad. Beck sostiene que se está en camino hacia una sociedad del riesgo, que define como "una fase de desarrollo de la sociedad moderna en la que los riesgos sociales, políticos, económicos e individuales tienden cada vez más a escapar a las instituciones de control y protección de la sociedad industrial'. BECK, U. La reinversión de la política: hacia una teoría de la modernización reflexiva (versión española de J. Alborés), en Modernización reflexiva. Política, tradición y estética en el orden social moderno. Madrid, 1994. Alianza Editorial. Pp. 18.
} 
Derecho Penal hacia la tutela de bienes jurídicos supraindividuales, como ocurre precisamente- con el medio ambiente. Para ello se fundan en los nuevos riesgos surgidos, con ocasión de los cambios experimentados a raíz de los avances tecnológicos y científicos de las últimas décadas, así como en la globalización y el dinamismo que dichos progresos conllevan. En concreto se sostiene que la sociedad moderna se caracteriza por su complejidad, transnacionalidad, dinamicidad en su economía, multiplicidad de interconexiones causales y existencia de una alta intervención de colectivos ${ }^{7}$, circunstancias que favorecen la aparición de nuevos peligros ante los que el ciudadano se siente amenazado y cuya mayor dañosidad se produce, particularmente, por la acumulación de los mismos. ${ }^{8}$

Producto de lo anterior han surgido los denominados bienes jurídicos macrosociales o colectivos, que -para muchos- justifican la actuación del Derecho Penal más allá de la lesión de los bienes jurídicos personales. Ello ha traído, como consecuencia, una expansión del ámbito de actuación clásica del Derecho Penal hacia campos que resultan ajenos a los tradicionales y en los que efectivamente se han disminuido o, al menos, atenuado algunas garantías propias de esta disciplina.

Ahora bien, tradicionalmente, los delitos de peligro se han clasificado como de peligro abstracto y de peligro concreto. Se trataría de un delito de peligro abstracto cuando se incumple una norma protectora del medio ambiente, en la que el peligro fue la motivación del legislador, aunque no forma parte del tipo infraccional ${ }^{9} \mathrm{y}$ de un peligro concreto, cuando en un caso específico se pone en peligro real y efectivo un sistema ecológico. En este último caso se requiere, por tanto, la comprobación de que la acción ha puesto en una situación de peligro real al bien jurídico protegido. ${ }^{10}$

A esta clasificación tradicional, debe agregarse una adicional. En efecto, el Tribunal Supremo español, a partir de 2003, aplica un concepto intermedio

${ }^{7}$ JIMENEZ DÍAZ, M. Sociedad del riesgo e intervención penal. Revista Electrónica de Ciencia Penal y Criminología. 2014, núm. 16-08, p. 08:1-08:25 - ISSN 1695-0194. Pp. 2.

${ }^{8}$ SERRANO TÁRRAGA, SERRANO MAÍLLO y VÁZQUEZ GONZÁLEZ enfatizan que si bien los riesgos contemporáneos son producto del proceso de modernización e industrialización, que ha creado nuevos riesgos, ellos se deben -por sobre todo- a la acumulación de los mismos. SERRANO TARRAGA, M., SERRANO MAÍLLO, A. y VÁZQUEZ GONZÁLEZ, C. Tutela penal ambiental. Madrid, 2013, $2^{\mathrm{a}}$ Ed. Dykinson. Pp. 27.

${ }^{9}$ En los delitos de peligro abstracto, el peligro es únicamente la ratio legis, es decir el motivo que indujo al legislador a crear la figura delictiva. Se castigan ciertas conductas porque generalmente llevan consigo el peligro de un bien jurídico. El peligro no es un elemento del tipo y el delito queda consumado, aunque en el caso concreto no se haya producido un peligro del bien jurídico protegido. CEREZO MIR, J. Los delitos de peligro abstracto en el ámbito del Derecho Penal del riesgo. Revista de Derecho Penal y criminología, 2a Época, $\mathrm{N}^{\circ} 10$ (2002). Pp. 47-72.

${ }^{10}$ En los delitos de peligro concreto, el peligro del bien jurídico es un elemento del tipo, de modo que el delito queda solo consumado cuando se ha producido realmente el peligro del bien jurídico. Desde el punto de vista dogmático, los delitos de peligro concreto son delitos de resultado. CEREZO MIR, J. Los delitos de peligro abstracto en el ámbito del Derecho Penal del riesgo. Op. Cit. Pp. 47-72. 
denominado delito de peligro hipotético, potencial o abstracto-concreto. Según dicha concepción, no solo es innecesario que se llegue a producir una lesión del bien jurídico que se pretende proteger, sino que ni siquiera el resultado del peligro ha de ser probado, bastando con que se acrediten los presupuestos del tipo y la potencialidad -en abstracto- del comportamiento para generar el peligro. ${ }^{11}$

Otro de los elementos característicos del Derecho Penal ecológico es la dependencia de otras ramas del ordenamiento jurídico que se manifiesta en la técnica legislativa denominada "leyes penales en blanco", porque recurren a normas extrapenales que completan el tipo sancionado en la norma penal. Esta dependencia puede producir una serie de problemas constitucionales, dado que -en ocasiones- el reenvío no se produce hacia leyes o normas del mismo rango. ${ }^{12}$ Asimismo, esta técnica legislativa ha sido cuestionada porque genera dudas acerca del cumplimiento del principio de legalidad, dado que la remisión a normas extrapenales para la integración del supuesto de hecho típico -sobre todo cuando emanan de autoridades administrativas- puede vulnerar el principio de reserva de ley y colisionar con el fundamento político-constitucional de este postulado, sustentado sobre la división de poderes y el paradigma democrático. ${ }^{13}$ Ello -según BRANDARIZ GARCIA- por cuanto se puede dejar en manos del Ejecutivo la selección de las conductas penalmente relevantes, al tiempo que se puede dar vida a un sector del Derecho Penal meramente accesorio respecto de la regulación administrativa, en el que se sancionarían infracciones de mera desobediencia. Del mismo modo, las leyes penales

${ }^{11}$ En consonancia con lo anterior, según CEREZO MIR, en la que denomina "moderna Ciencia del Derecho penal" existiría un grupo de delitos de peligro llamados de aptitud para la producción de un daño o de peligro abstracto-concreto. Se trataría de figuras delictivas en las que se prohíbe la realización de una acción que lleve implícita la posibilidad de producir un determinado resultado. En opinión del autor, este sería el caso de la mayor parte de los delitos contra los recursos naturales y el medio ambiente en España. CEREZO MIR, J. Los delitos de peligro abstracto en el ámbito del Derecho Penal del riesgo. Op. Cit. Pp. 47-72. Por su parte, MUNOZ CONDE se refiere a un delito hipotético, a medio camino entre los delitos de peligro abstracto y concreto, en el que, si bien no es necesario demostrar una situación de peligrosidad concreta, la conducta debe presentar, al menos, una aptitud lesiva que la cualifique frente a las simples infracciones administrativas. MUÑOZ CONDE, F. Derecho Penal, Parte Especial. Valencia, 2015. 20 Ed. Tirant lo Blanch. Pp. 500 y 501

${ }^{12}$ La utilización de leyes penales en blanco constituye una cuestión polémica en la doctrina contemporánea. Ello, en la medida en que no contienen una descripción cerrada del supuesto de hecho prohibido, de modo que conforman normas incompletas que requieren la integración con otra instancia reguladora, de naturaleza - en principio - legal o reglamentaria. BRANDARIZ GARCIA, J.A. La problemática de las normas penales en blanco, en Faraldo Cabana, P. (Dir.) / Puente Aba, L.M. (Coord.), Ordenación del territorio, patrimonio histórico y medio ambiente en el Código penal y la legislación especial. Valencia, 2011. Tirant lo Blanch. Pp. 106-119.

${ }^{13}$ En España, el Tribunal Constitucional ha zanjado las dudas planteadas en relación con las leyes penales en blanco estableciendo que la norma penal debe contener el núcleo esencial de la prohibición de la conducta ilícita, pudiendo dejar a normas extrapenales la determinación concreta de las modalidades comisivas, remisión que, en todo caso, debe ser expresa. 
en blanco también plantean problemas desde la perspectiva del mandato de taxatividad impuesto a las normas penales, porque el reenvío a otras instancias, propiciando disposiciones notablemente incompletas, dificulta el conocimiento de la materia de prohibición y pone en peligro la seguridad jurídica. ${ }^{14}$

\section{Principio de intervención mínima (ultima ratio)}

El principio de intervención mínima se funda en la especial gravedad de las consecuencias penales, de su carácter de último recurso dentro del sistema de control social y de la propia comprensión de la pena, como un mal que solo puede justificarse por su necesidad para mantener los presupuestos de convivencia social, de manera que debe reservarse para aquellos casos en que sea imprescindible para cumplir la finalidad de protección de los bienes jurídicos más relevantes, encomendada al Derecho Penal. ${ }^{15}$ Así, el principio de intervención mínima implica que "el Derecho penal solo debe intervenir en los casos de ataques muy graves a los bienes jurídicos más importantes" ${ }^{16}$, es decir, apunta a que esta herramienta debe ser el último instrumento al que la sociedad recurre para proteger determinados bienes jurídicos y en la medida que no existan otras formas de control menos lesivas. ${ }^{17}$ Sin embargo, una de las características del llamado Derecho Penal moderno y del Derecho Penal medioambiental (que corresponde a las sociedades de riesgo), pareciera ser su carácter de prima ratio. Ello se traduce en una tendencia expansiva o "huida" al Derecho Penal, mediante la incorporación -a veces excesiva- de bienes jurídicos colectivos y delitos de peligro. En efecto, en la actualidad puede apreciarse un aumento del intervencionismo penal en la práctica político criminal del Estado, ya sea a través de agravación de las penas, la ampliación del tenor de los tipos o la inclusión de nuevos delitos, todo ello como parte de una tendencia más o menos generalizada a la extensión del Derecho Penal, especialmente en lo que respecta a

\footnotetext{
${ }^{14}$ BRANDARIZ GARCIA, J.A. La problemática de las normas penales en blanco. Op. Cit. Pp. 106-119.

${ }^{15}$ MUÑOZ CONDE, F., LÓPEZ PEREGRÍN, C. y GARCÍA ALVAREZ, P. Manual de Derecho Penal medioambiental. 2 a Edición, Valencia, 2015. Ed. Tirant lo Blanch. Pp.50.

${ }^{16}$ MUÑOZ CONDE, F. y GARCÍA ARÁN, M. Derecho Penal, Parte General. Valencia, 2015. Ed. Tirant lo Blanch. Pp. 77.

${ }^{17}$ En términos similares, para BLANCO LOZANO este principio significa que "el Derecho Penal no interviene de cara a la regulación de todos los comportamientos del hombre en sociedad, sino solo en orden a evitar los atentados más graves que se dirijan contra importantes bienes jurídicos. El principio de intervención mínima supone, por tanto, que la esfera de regulación de esta rama del Ordenamiento jurídico debe verse (...) reducida al máximo en cuanto a su extensión". BLANCO LOZANO, C. Derecho Penal, Parte General. Madrid, 2003. Ed. La Ley Pp.122.
} 
algunas materias o actividades tradicionalmente reguladas por otras ramas del ordenamiento, como el Derecho Administrativo sancionador. ${ }^{18}$

Una muestra de lo anterior, son las reflexiones que el propio Tribunal Supremo de España ha efectuado en relación con el principio de intervención mínima -en materia de medio ambiente- preconizando una aplicación restrictiva del mismo en la praxis judicial. ${ }^{19}$

Ahora bien, no obstante que -en la actualidad- la incorporación de nuevos tipos penales forma parte de un desarrollo normal y lógico, dado que los riesgos y las necesidades sociales varían con el tiempo, debe tenerse especial cuidado con esta expansión y, en particular, con la debida justificación de las nuevas modalidades de intervención penal, porque no son pocos los casos en que las autoridades recurren al Derecho Penal con premura, antes de dilucidar siquiera si se presenta una real necesidad preventiva de punición y si existen otros mecanismos de control social apropiados e, incluso, sin haber ponderado la jerarquía del bien jurídico que se pretende salvaguardar. ${ }^{20}$ El Derecho Penal no puede ser manipulado con fines políticos, ni puede utilizarse solo para efectos comunicativo-educativos, así como tampoco debe ser empleado como una herramienta de transformación de la sociedad, vale decir, para conseguir un mayor progreso social, económico o cultural. Ello, porque todos estos usos -en nuestra opinión inadecuados- del Derecho Penal podrían implicar la privación injustificada o desproporcionada de derechos y garantías individuales, circunstancia que, a largo plazo, podría tener consecuencias nocivas para la credibilidad y el funcionamiento del sistema penal. En efecto, la intervención del Derecho Penal es demasiado profunda y lesiva como para instrumentalizarla, empleándola para finalidades que no le son propias, de manera que, a nuestro juicio, debe mantenerse firme, en una relación de subsidiariedad respecto de las demás herramientas coercitivas de que dispone el Estado. Lo anterior, evidentemente, no obsta a que el Derecho Penal tenga efectos simbólicos. Es más, en la práctica, la intimidación penal siempre conlleva un efecto comunicativo-simbólico. Sin embargo, lo que no puede ocurrir es que las normas penales resulten incapaces de cumplir sus efectos legítimos -en relación con la protección de bienes jurídicos-y que, por tanto,

18 Así, por ejemplo, SERRANO TÁRRAGA, SERRANO MAÍLLO y VÁZQUEZ GONZÁLEZ destacan que el principio de intervención mínima se encuentra en una muy grave crisis, si es que aún no se ha abandonado de hecho. SERRANO TÁRRAGA, M., SERRANO MAÍLLO, A. y VÁZQUEZ GONZÁLEZ, C. Tutela penal ambiental. Op. Cit. Pp. 47.

${ }^{19}$ SERRANO TÁRRAGA, M., SERRANO MAÍLLO, A. y VÁZQUEZ GONZÁLEZ, C. Tutela penal ambiental. Op. Cit. Pp. 110.

${ }^{20}$ No todo bien jurídico puede ser objeto de disposiciones penales legítimas porque, en primer lugar, el sistema penal no siempre cuenta con los mecanismos adecuados para proteger ciertos bienes jurídicos y, por otra parte, porque no resulta adecuado para solventar los problemas de carácter holista que aquejan a la sociedad, puesto que está configurado como un sistema de imputación de conductas lesivas individuales. OSSANDÓN WIDOW, M. Eficiencia del Derecho Penal. El caso de los delitos contra el medio ambiente. Revista de Derecho de la Pontificia Universidad Católica de Valparaíso, XXIV (Valparaíso, Chile, 2003) Pp. 379-394. 
la función comunicativo-simbólica o educativa aparezca como su principal consecuencia. $^{21}$

\section{Principio non bis in idem}

En la actualidad, El principio non bis in idem tiene plena vigencia y respecto del que, puede decirse, se ha acomodado a las circunstancias y exigencias de nuestra época. ${ }^{22}$ Ejemplo de ello es que, hoy por hoy, no se trata de un marco de acción exclusivo en el Derecho Penal como en el origen, sino que -por el contrario- se aplica en otros ámbitos en que se manifiesta el poder sancionador del Estado.

El significado literal del aforismo latino non bis in idem es "no dos veces lo mismo". Por ello suele entenderse como la prohibición del doble castigo por el mismo ilícito, es decir, que un sujeto no puede ser sancionado dos o más veces por el mismo hecho sobre la base del mismo fundamento. De este modo, el principio non bis in idem constituye -conforme a los principios de culpabilidad y de seguridad jurídicauna de las garantías que asiste a la persona, ante el ejercicio del poder punitivo estatal, cuya finalidad es evitar que se le someta al riesgo de ser procesada o sancionada en dichas circunstancias. ${ }^{23}$ Atendido lo anterior es que en materia medio ambiental, el non bis in idem, constituye un principio de gran relevancia, pues permite "solucionar" los supuestos de duplicidad sancionadora que se pueden dar, debido a la dependencia del Derecho Penal respecto del administrativo.

\section{Responsabilidad penal de las personas jurídicas}

Debido a que la responsabilidad penal es esencialmente de carácter subjetivo, tradicionalmente se había reconocido el principio societas delinquere non potest $\mathrm{o}$, expresado también de otro modo, universitas delinquere nequit, rechazándose la imputación de responsabilidad penal de las personas jurídicas y considerándose que en los casos de comisión de un delito en el seno o bajo el amparo de una empresa, la responsabilidad criminal alcanzaba únicamente a las personas físicas que actuaban

\footnotetext{
${ }^{21}$ Los efectos instrumentales son aquellos que están directamente relacionados al fin o función de protección de bienes jurídicos y se vinculan con la capacidad de prevenir determinados comportamientos. Por su parte, los efectos simbólicos están conectados al fin o función de transmitir mensajes o contenidos valorativos, produciendo emociones y representaciones mentales.

${ }^{22}$ RAMIREZ TORRADO, M. El non bis in idem en el ámbito administrativo sancionador. Revista de Derecho No 40, Barranquilla, 2013 ISSN: 0121-8697 (impreso) Pp. 3.

${ }^{23}$ PINEDO HIDALGO, P. ¿Vulneración del non bis in idem mediante la aplicación de consecuencias accesorias a las personas jurídicas? Pp. 2.

Disponible en https://www.unifr.ch/ddp1/derechopenal/articulos/a_20110907_01.pdf
} 
por aquella. ${ }^{24}$ Sin embargo, en nuestra época, en la denominada sociedad de riesgos, el dinamismo de las grandes organizaciones empresariales y su compleja estructura que, en muchas ocasiones, es transnacional, así como los modelos de gestión corporativa imperantes y los incentivos (a veces perversos) otorgados a sus ejecutivos, han generado nuevos peligros para bienes jurídicos de interés colectivo y nuevos problemas de imputación, resultando de gran complejidad la determinación de los sujetos implicados ${ }^{25}$. En consecuencia, la tendencia internacional que es posible apreciar por la incorporación de la responsabilidad penal de las personas jurídicas responde, esencialmente, a criterios político-criminales vinculados al fenómeno de la denominada criminalidad empresarial ${ }^{26}$, propia de las sociedades contemporáneas. ${ }^{27}$

En concreto, los argumentos que se han dado para justificar la necesidad de la responsabilizar penalmente a las personas jurídicas podrían resumirse en: (a) Existencia de dificultades prácticas para exigir responsabilidad penal a las personas físicas insertas en una persona jurídica, así como el alivio de tensiones al sistema de responsabilidad individual, porque no habría que forzar en exceso categorías dogmáticas o bien porque posibilitaría una reducción del rigor punitivo con las personas físicas ${ }^{28}$; (b) Existencia de necesidades preventivas, dado que la

\footnotetext{
${ }^{24}$ Históricamente, la responsabilidad colectiva, de grupo o social se había reconocido para algunos delitos desde el Código de Hammurabi y posteriormente en Grecia, pero ya no en Roma (a pesar de que aparecen los primeros gérmenes de la personalidad jurídica a través de la universitas, ente capaz de adquirir derechos y contraer obligaciones). Igualmente estuvo vigente en el Derecho germánico y francés, así como en el Derecho canónico. Lo estuvo también en España durante la Edad Media en varios fueros (León, Navarra y Nájera). Pero las revoluciones francesa y norteamericana establecieron las bases del liberalismo individual y, a raíz de ello, en los Códigos europeos del s. XIX desapareció toda referencia a una posible responsabilidad colectiva. BOLDOVA PASAMAR, M. La introducción de la responsabilidad penal de las personas jurídicas en la legislación española. Estudios Penales y Criminológicos Vol. XXXIII. Universidad de Santiago de Compostela/ Servicio de Publicaciones e Intercambio Científico. Pp. 220 y 221.

${ }^{25}$ SZCZARANSKI CERDA, C. Un asunto criminal contemporáneo. Rol de las empresas, responsabilidad penal de las personas jurídicas y corrupción. Santiago, 2011. Ed. Jurídica de Chile. Pp. 31.

${ }^{26}$ Un estudio de Max-Planck-Institut für ausländisches und internationales Strafrecht de Friburgo de Brisgovia señala que, entre los años 1964 y 1985, más del 80\% de los delitos económicos se cometen a través de sociedades. RODRÍGUEZ MOURULLO, G. El fundamento de la responsabilidad penal de las personas jurídicas según la Circular 1/2011 de la Fiscalía General del Estado. Op. Cit. Pp. 191.

${ }^{27}$ FRAGA GOMEZ, O. Responsabilidad penal de las personas jurídicas. Los modelos de organización y gestión, "Compliance", en el proyecto de reforma del Código Penal de 2013. Cuaderno Electrónico de Estudios Jurídicos. Núm. 1, Año 2013 (Diciembre). Pp. 43 - 80.

${ }^{28}$ DÍAZ RIPOLLES, J.L. La responsabilidad penal de las personas jurídicas. Regulación española. Indret: Revista para el Análisis del Derecho, ISSN-e 1698-739X, Nº 1.Pp. 3. En el mismo sentido, BOLDOVA PASAMAR, M. en La introducción de la responsabilidad penal de las personas jurídicas en la legislación española. Op. Cit. Pp. 226 y NIETO MARTíN, A. en La responsabilidad penal de las personas jurídicas: un modelo legislativo. Madrid, 2008. Ed. Iustel. Pp. 42 ss., quienes sostienen que el principal objetivo de la responsabilidad colectiva
} 
responsabilidad penal individual, o la colectiva del Derecho Administrativo sancionador, tendrían escaso efecto preventivo en la empresa; (c) Necesidad de implicar a los entes colectivos en la prevención y persecución de delitos cometidos en su seno, porque los órganos de la Administración pública ya no estarían en condiciones de llevar a cabo esas funciones con eficacia, debido a la complejidad tecnológica y organizativa que han adquirido los entes colectivos.

\section{Cuestionamientos dogmáticos}

Las principales causas por las que se ha negado la posibilidad de que las personas jurídicas puedan incurrir en responsabilidad penal se refieren a la supuesta incapacidad de acción, de culpabilidad y de pena de que adolecerían las referidas entidades. Al respecto $\mathrm{y}$, en términos generales, se señala que exigirles dicha responsabilidad quebrantaría los principios de personalidad de las penas y de culpabilidad, porque se les atribuiría una acción y una culpabilidad que no es propia, sino que correspondería a la(s) persona(s) física(s) que la dirige(n) o que la gestiona(n). De este modo se sostiene, en primer lugar, que las personas jurídicas son incapaces de actuar, por lo que a ellas solo se les imputan acciones (u omisiones) producidas y dirigidas por otros, en general, sus órganos decisorios o la administración, ambos constituidos por personas físicas. MORILLAS CUEVA se refiere a la incapacidad de acción, en cuanto conducta humana, que es motivada por una "voluntad", es decir, se refiere a un querer propio, del que es incapaz el ente colectivo, sino por medio de sus representantes físicos que son los que -en definitivapueden materializar los actos delictivos. ${ }^{29}$ Por otra parte y en lo tocante a la incapacidad de culpabilidad, la doctrina advierte que el reproche en que se funda esta última ha sido construido para los individuos, de manera que resultaría incompatible con la naturaleza de los entes colectivos ${ }^{30}$, porque no pueden conocer y comprender la ilicitud de su conducta ni ordenar su actuación en atención a ese conocimiento. De esta forma, quienes niegan la posibilidad de imputar responsabilidad penal a los entes morales, sostienen que solo la persona física (único sujeto con plena capacidad intelectiva y volitiva) puede diseñar y ejecutar la conducta ilícita, cuyo reproche se materializa mediante la imposición de una pena individual. Finalmente, la doctrina destaca que junto a la incapacidad de acción y de culpabilidad se encuentra una tercera incapacidad y que es consecuencia de ambas: la incapacidad de pena, fundada

sería incentivar la autorregulación dirigida a la prevención del delito en el seno del ente colectivo, ante la incapacidad de los Estados para realizar eficazmente dicha función, y efectuar una administración a largo plazo de los riesgos modernos.

${ }_{29}$ MORILLAS CUEVA, L. La cuestión de la responsabilidad penal de las personas jurídicas. Anales de Derecho. Número 29, 2011. Pp. 10.

${ }^{30}$ ABANTO VÁSQUEZ, M. Responsabilidad penal de los entes colectivos: una revisión crítica de las soluciones penales. Revista penal, ISSN 1138-9168, N 26, 2010. Pp. 3 - 45. 
-principalmente- en el principio de personalidad que se le atribuye, en el reproche ético-social que supone su imposición en el ámbito penal y en sus propios fines tanto preventivo generales, ya que los entes morales no padecen y, por tanto, no son susceptibles de coacción psicológica (propia de la prevención general negativa), ni de valorar su actitud de respeto a la norma (de la prevención general positiva), como preventivo especiales, dado que la persona jurídica escapa a la idea de resocialización. ${ }^{3}$

Así, a modo de síntesis, quienes se oponen a la responsabilidad penal de las personas jurídicas, lo hacen con base en un único argumento, pero -coincidiendo con MOLINA FERNÁNDEZ- muy contundente: si el delito requiere imputación subjetiva/culpabilidad, entonces las personas jurídicas no pueden delinquir ni sufrir penas, porque les faltan los atributos subjetivos necesarios para realizar tal juicio de imputación. ${ }^{32}$

${ }^{31}$ MORILLAS CUEVA, L. La cuestión de la responsabilidad penal de las personas jurídicas. Op. Cit. Pp. 11.

${ }^{32}$ MOLINA FERNÁNDEZ, F. Societas peccare non potest...nec delinquere, en Estudios de Derecho Penal, Homenaje al profesor Miguel Bajo, Madrid, 2016. Ed. Centro de Estudios Ramón Areces. Pp. 362. En sentido contrario, ZUGALDÍA ESPINAR sostiene que el argumento para descartar la aplicación del Derecho Penal a las personas jurídicas, adolece de una gran debilidad teórica porque parte de un "presupuesto metodológico totalmente erróneo". Al respecto, indica que (i) las personas jurídicas son incapaces de acción, pero solo si a la acción se la define exclusivamente como comportamiento humano; (ii) las personas jurídicas son también incapaces de culpabilidad, pero solo si a la culpabilidad se le entiende exclusivamente en clave bío-psicológica; y (iii) las personas jurídicas son incapaces de pena, pero solo si a ésta se la concibe como castigo retributivo del mal uso de la libertad humana. De este modo, argumenta que -al margen de estos conceptos de acción y de culpabilidad exclusivos de la persona física- existen también unos conceptos de acción y de culpabilidad propios de la persona jurídica sobre los que es posible exigirle responsabilidad criminal sin violar ningún principio constitucional, lo que corrobora que el tema de la responsabilidad criminal de las personas jurídicas "no es un problema ontológico, sino un simple problema de definición". Asimismo, quienes defienden la responsabilidad penal de los entes morales y, particularmente, ZUGALDIA ESPINAR, sostienen que nunca se ha llegado a explicar por qué, a diferencia de lo que ocurre con los cuestionamientos surgidos en relación con el Derecho Penal, la imposición de sanciones de índole administrativas a las personas jurídicas no transgrede el principio de personalidad de las penas y el de culpabilidad, si se trata de las mismas sanciones e incluso más graves, pero con otro nombre. Este autor en concreto, agrega que, si se fuera coherente, habría que admitir que las personas jurídicas no pueden ser sancionadas en absoluto. ZUGALDIA ESPINAR, J.M. Aproximación teórica y práctica al sistema de responsabilidad criminal de las personas jurídicas en el Derecho Penal español. Op. Cit. Pp. 2 


\section{Modelos de imputación}

En términos generales, puede señalarse que los intentos doctrinales encaminados a justificar la imposición de sanciones penales a las personas jurídicas son de dos clases: la heterorresponsabilidad (modelo de responsabilidad por atribución, vicarial o transferencia desde la persona física a la persona jurídica) y la autorresponsabilidad (modelo de responsabilidad directa $u$ originaria de la persona jurídica).

\subsection{Modelo de responsabilidad por atribución (Modelo vicarial)}

El sistema vicarial o de transferencia de responsabilidad es el más antiguo de los modelos de responsabilidad penal de las personas jurídicas ${ }^{33}$ y supone la transmisión de la responsabilidad de un agente (persona natural) a la empresa (persona jurídica) con la que mantiene alguna relación funcional definida en la ley. En otras palabras, el modelo de responsabilidad por atribución supone que el hecho ilícito es llevado a cabo por una persona física que forma parte de la empresa o que tiene alguna vinculación relevante con la persona jurídica (normalmente, aunque no siempre, por alguna de las integran sus órganos o la representan), de modo que la responsabilidad por la comisión del mismo se transfiere también a esta última. En consecuencia, el sistema vicarial parte del entendido de que, si bien las personas jurídicas no pueden actuar ni ser por si mismas culpables, ellas pueden ser responsabilizadas de manera directa por las acciones o culpabilidad de alguno de sus agentes, en la medida que se cumplan determinadas condiciones. Estas condiciones de transferencia son independientes de la propia persona jurídica y se relacionan, en términos generales, con la posición del agente en la persona jurídica, así como con el provecho o beneficio que su acción podría haberle reportado al ente colectivo.

\subsection{Modelo de autorresponsabilidad}

El segundo modelo de imputación corresponde al de autorresponsabilidad, que trata de articular la responsabilidad sobre la base de un injusto propio y/o de una culpabilidad propia de la persona jurídica, totalmente independiente de los de la persona física ${ }^{34} \mathrm{o}$, en otros términos, intenta construir una culpabilidad penal propia e

${ }^{33}$ NIETO MARTIN, A. Responsabilidad penal de las personas jurídicas: un modelo legislativo. Op. Cit. Pp. 85; GOMEZ-JARA, C. La responsabilidad penal de las empresas en los Estados Unidos. Madrid, 2006. Editorial universitaria Ramón Areces. Pp. 43.

${ }^{34}$ BOLDOVA PASAMAR, M. La introducción de la responsabilidad penal de las personas jurídicas en la legislación española. Op. Cit. Pp. 232. 
independiente de la empresa, que se considera jurídicamente autónoma de la que pueda imputarse a las personas naturales o físicas que la controlan o actúan por ella. ${ }^{35}$

Si bien la doctrina ha realizado grandes esfuerzos por configurar distintos injustos propios de la persona jurídica, la mayoría se ha decantado por la culpabilidad de la empresa como defecto de organización, es decir, por no haberse generado en ella un sistema preventivo destinado a prevenir de modo razonable los riesgos derivados de la actividad empresarial. ${ }^{36}$

\subsection{Modelo de imputación chileno y español}

Tanto el modelo chileno como español recogen -en su base- el sistema vicarial, pues en ambos casos la criminalización de las empresas se sustenta en los delitos que hubieren cometido determinadas personas físicas vinculadas a la empresa. Asimismo, en ambos ordenamientos jurídicos, la existencia de programas de cumplimiento constituye un elemento gravitante a la hora de sancionar penalmente a los entes morales. En España, constituyen un eximente de responsabilidad criminal si se verifican los supuestos establecidos en el Código Penal y, en Chile por su parte, permiten acreditar la presunción de haber cumplido con los deberes de dirección y supervisión establecida a favor de las personas jurídicas.

\section{Legislación del Medio Ambiente en Chile}

\subsection{Delitos contra el medio ambiente y recursos naturales. Marco constitucional y situación actual}

Sin duda el acontecimiento legislativo más importante en nuestro país, desde la óptica de la normativa ambiental, es la consagración de la protección del medio

\footnotetext{
${ }^{35}$ VAN WEEZEL, A. Contra la responsabilidad de las personas jurídicas. Polít. crim. Vol. 5, $\mathrm{N}^{\mathrm{a}} 9$ (Julio 2010), Art. 3, pp. 114-142. Disponible en http://www.politicacriminal.cl/Vol_05/n_09/Vol5N9A3.pdf

${ }^{36}$ BOLDOVA PASAMAR, sostiene que solo el defecto de organización podría representar un injusto propio y singular de la persona jurídica. En este escenario, según el autor, esos defectos organizativos deberían constituir por sí mismos los respectivos delitos societarios. Así, señala que esos defectos podrían ser dolosos (preordenados) o imprudentes (mala planificación), pero si se presentan al margen de un hecho o hechos delictivos concretos (condición objetiva de punibilidad), carecerían per se de entidad y relevancia penal para constituir un delito. BOLDOVA PASAMAR, M. La introducción de la responsabilidad penal de las personas jurídicas en la legislación española. Op. Cit. Pp. 232. También se manifiesta conforme con este modelo ZUGALDÍA ESPINAR, quien destaca que la propuesta que TIEDEMANN ha denominado "culpabilidad por defecto de organización" se trata de una construcción preferible por haber logrado una aceptación prácticamente generalizada en la doctrina. ZUGALDIA ESPINAR, J.M. Aproximación teórica y práctica al sistema de responsabilidad criminal de las personas jurídicas en el Derecho Penal español. Op. Cit. Pp. 3.
} 
ambiente a nivel constitucional; circunstancia que ocurrió -de manera explícita- por primera vez en la Constitución Política de 1980. En efecto, la Constitución vigente hasta la fecha, a propósito del reconocimiento y establecimiento de los derechos y deberes constitucionales (art. $19 \mathrm{~N}^{\mathrm{o}} 8$ ), se encarga de asegurar por primera el derecho a vivir en un medio ambiente libre de contaminación, imponiendo al Estado el deber de "velar para que este derecho no sea afectado y tutelar la preservación de la naturaleza" y facultando a la ley para establecer "restricciones específicas al ejercicio de determinados derechos o libertades para proteger el medio ambiente". Sin embargo, hasta hoy, en Chile no existe una protección penal sistemática y enfocada a la protección del medio ambiente como bien jurídico, sino que nuestra legislación penal en esta materia se encuentra en un estado de desarrollo que puede denominarse de "prescindencia", en que la regulación de conductas atentatorias que podrían considerarse como de contaminación o peligro de contaminación o daño ambiental, se encuentra dispersa en el Código Penal y en diversas leyes especiales, en las que no han sido establecidas directa e independientemente con ese propósito, sino que con la finalidad de proteger otros bienes, pero que -al momento de la codificación o al de dictarse las leyes especiales- se consideraron como dignos de una protección penal. $^{37}$

\subsection{Ley de base del medio ambiente}

Sin perjuicio que el derecho a un medio ambiente libre de contaminación, así como la obligaciones del Estado de velar para que este derecho no sea afectado y tutelar la preservación de la naturaleza, fue consagrado en 1980, no fue sino hasta 1994 que se estableció un sistema legal de tutela ambiental, mediante la promulgación de la Ley sobre Bases Generales del Medio Ambiente (Ley No 19.300), sumándose tardíamente- a un proceso de institucionalización de la protección del medio ambiente que se había desarrollado internacionalmente, a partir de la década de los años setenta. El sistema creado por la redacción original de la Ley $\mathrm{N}^{\circ} 19.300$ incluyó dos elementos de gran trascendencia. El primero de ellos, fue la creación del Sistema de Evaluación de Impacto Ambiental, instrumento de gestión al cual deben someterse los proyectos de inversión y/o actividades productivas, con el fin de determinar los impactos que tendrán sobre el medio ambiente y los recursos naturales presentes en el área de afectación; y, el segundo, la creación de la hoy extinta Comisión Nacional del Medio Ambiente ("CONAMA"), ente que reunía importantes competencias

${ }^{37}$ MATUS ACUÑA, J.P., ORELLANA CRUZ, M., CASTILLO SÁNCHEZ, M. y RAMÍREZ GUZMÁN, M. (2003). Análisis dogmático del Derecho Penal ambiental chileno, a la luz del derecho comparado y las obligaciones contraídas por Chile en el ámbito del derecho internacional: conclusiones y propuesta legislativa fundada para una nueva protección penal del medio ambiente en Chile. Ius et Praxis, 9(2), 11-57. Disponible en https://dx.doi.org/10.4067/S0718-00122003000200002 
ambientales (evaluación ambiental de proyectos, dictación de normas de contenido ambiental, diseño de políticas ambientales y fiscalización, entre otras). La creación del referido organismo, sin suprimir las competencias de los servicios públicos en materia ambiental, fundó las bases para una institucionalidad transversal y de carácter coordinador. Sin embargo, el modelo institucional que se implantó originalmente, implicaba una inspección ambiental realizada por diversos servicios públicos, en la que CONAMA se encontraba frente a diferentes metodologías y sin poder rector de la fiscalización ambiental.

Atendido lo anterior, el Informe de Evaluación del Desempeño Ambiental realizado por la OCDE, respecto al período de evaluación realizado entre 1990-2004, incluyó una serie de recomendaciones al Gobierno de Chile, entre las que destacan el "desarrollar y fortalecer las instituciones ambientales en los ámbitos nacional y regional". Del mismo modo, la OCDE hizo un llamado a fortalecer "la capacidad de cumplimiento y fiscalización, incluso mediante reformas institucionales, como por ejemplo, el establecimiento de un órgano de inspección ambiental'. Así, tras las sugerencias de la OCDE y la publicación de Ley $\mathrm{N}^{\mathrm{o}} 20.417$ en el año $2010^{38}$, en virtud de la cual se realizaron profundas modificaciones a la Ley $\mathrm{N}^{\circ} 19.300$, se reemplazó la CONAMA por tres instituciones dotadas de responsabilidades específicas en materia de formulación de políticas, evaluación ambiental y fiscalización del cumplimiento de las normas ambientales, con el propósito de fortalecer la capacidad de estas importantes funciones: (a) El Ministerio del Medio Ambiente ("MMA") es responsable del diseño de políticas, la redacción de normas y la gestión de la información en materia medioambiental, y tiene una fuerte presencia regional. (b) El Servicio de Evaluación Ambiental ("SEA") es un organismo técnico descentralizado que funciona bajo la órbita del MMA y está encargado de administrar el Sistema de Evaluación de Impacto Ambiental, incluido un sistema de información sobre permisos ambientales. (c) La Superintendencia del Medio Ambiente ("SMA"), servicio público descentralizado responsable de la fiscalización ambiental y de velar por el cumplimiento de las normas ambientales. En concreto, la SMA tiene la autoridad de fiscalizar el cumplimiento de las Resoluciones de Calificación Ambiental ("RCA") ${ }^{39}$, Normas de Calidad y Emisión, Planes de Prevención y/o Descontaminación, Planes de Manejo de la Ley $\mathrm{N}^{\circ} 19.300$, entre otras facultades. Adicionalmente, tiene la facultad exclusiva de aplicar sanciones frente a un incumplimiento de dichos instrumentos, las que van desde la amonestación por

\footnotetext{
${ }^{38}$ Ley Orgánica de la Superintendencia de Medio Ambiente.

${ }^{39} \mathrm{La} \mathrm{RCA}$ es la resolución administrativa que se obtiene una vez culminado el proceso de evaluación de los proyectos o actividades que deben someterse a Evaluación de Impacto Ambiental, ya sea a través de un Estudio de Impacto Ambiental (EIA) o de una Declaración de Impacto Ambiental (DIA).
} 
escrito hasta la revocación de la RCA, incluyendo la aplicación de multas de hasta 10.000 Unidades Tributarias Anuales ${ }^{40}$ (aprox. USD 9 Millones).

\subsection{Principales funciones de la Superintendencia de Medio Ambiente}

La misión que la SMA se atribuye es la "protección del medio ambiente y la salud de las personas, asegurando el cumplimiento de la normativa ambiental en Chile" a través de la optimización de la fiscalización ambiental, el perfeccionamiento de la respuesta sancionatoria y la promoción de su cumplimiento, así como la transmisión de la información a la comunidad. Para lograr con su cometido, la SMA realiza dos labores primordiales. La primera tarea es una labor fiscalizadora, que tiene por objeto verificar y promover el cumplimiento de la normativa ambiental, en base a un programa anual de fiscalización; y la segunda, es la función sancionadora, es decir, a través de la que se castiga a los sujetos que incumplen la normativa ambiental $\mathrm{y}$, al mismo tiempo, se promueve su cumplimiento. Esta última herramienta es fundamental para provocar el anhelado efecto disuasivo que logre desincentivar el incumplimiento de las normativas medioambientales.

Ahora bien, para efectos del ejercicio de la potestad sancionadora que corresponde a la SMA, las infracciones se clasifican en gravísimas, graves y leves ${ }^{42}$ y la escala de

${ }^{40}$ Corresponde a aquella unidad tributaria mensual (UTM) vigente en el último mes del año comercial respectivo, multiplicada por doce o por el número de meses que comprende el citado año comercial.

${ }^{41}$ SUPERINTENDECIA DEL MEDIO AMBIENTE. 2016. Cuenta Pública 2015. Pp. 7.

42 Conforme a la Ley, son infracciones gravísimas los hechos, actos u omisiones que contravengan las disposiciones pertinentes y que alternativamente: (i) Hayan causado daño ambiental, no susceptible de reparación. (ii) Hayan afectado gravemente la salud de la población. (iii) Impidan u obstaculicen deliberadamente el cumplimiento de metas, medidas, y objetivos de un Plan de Prevención o Descontaminación. (iv) Hayan entregado información falsa u ocultado cualquier antecedente relevante con el fin de encubrir u ocultar una infracción gravísima. (v) Hayan impedido deliberadamente la fiscalización, encubierto una infracción o evitado el ejercicio de las atribuciones de la SMA. (vi) Involucren la ejecución de proyectos o actividades que debiendo someterse al Sistema de Evaluación de Impacto Ambiental se mantengan al margen del mismo y se constate en ellos alguno de los efectos, características o circunstancias que obligaban a su titular a la realización de un Estudio de Impacto Ambiental. (vii) Constituyan reiteración o reincidencia en infracciones calificadas como graves. Por otra parte, son infracciones graves, los hechos, actos $\mathrm{u}$ omisiones que contravengan las disposiciones pertinentes y que, alternativamente: (i) Hayan causado daño ambiental, susceptible de reparación. (ii) Hayan generado un riesgo significativo para la salud de la población. (iii) Afecten negativamente el cumplimiento de las metas, medidas y objetivos de un Plan de Prevención y, o de Descontaminación. (iv) Involucren la ejecución de proyectos o actividades que debían someterse al Sistema de Evaluación de Impacto Ambiental y se mantengan al margen del mismo, si no están comprendidos en los supuestos del literal (vi) anterior. (v) Incumplan gravemente las medidas para eliminar o minimizar los efectos adversos de un proyecto o actividad, de acuerdo a lo previsto en la respectiva RCA. (vi) Conlleven el no acatamiento de las instrucciones, requerimientos y medidas urgentes 
sanciones que puede aplicar es muy amplia, dependiendo de la gravedad de las mismas. Ellas van desde la revocación de la RCA, circunstancia que en la práctica es casi equivalente a la disolución de la persona jurídica, pues implica la paralización de todas las operaciones del infractor, hasta la amonestación por escrito. A ello se suman, evidentemente, las altísimas multas -a beneficio fiscal- que pueden imponerse.

Por último, cabe hacer presente que para la determinación de las sanciones administrativas aplicables en cada caso particular, en 2015, la SMA aprobó y publicó las bases metodológicas para la determinación de sanciones ambientales, fundadas en la Teoría de las Sanciones Óptimas, elaborada por el destacado economista Gary Becker, premio Nobel de Economía. En base a dicha teoría, la SMA considera dos enfoques para la imposición de sanciones. El primero es el enfoque compensatorio (la sanción óptima es aquella que permite compensar el costo social de la infracción, analizando el daño causado a la sociedad y los costos de reparación de los efectos que dicho daño generó en ella y en el medioambiente); y el segundo, es el enfoque disuasivo (la sanción óptima será aquella que logre influir en la conducta que adoptará un potencial infractor para maximizar sus utilidades). ${ }^{43}$ En otros términos, $\mathrm{y}$ bajo este entendido, el cumplimiento de la legislación ambiental debe reportar al potencial infractor un mayor beneficio que el que puede obtenerse a raíz de su incumplimiento, vale decir, la sanción óptima debe ser mayor a las utilidades obtenidas ilícitamente por el agente.

\section{Conclusiones}

1) La necesidad de protección del medio ambiente ha cobrado una especial relevancia en las últimas décadas y por ello se ha producido un permanente debate acerca de la forma y mecanismos idóneos para el logro de este objetivo. En este contexto, el recurso al Derecho penal, como herramienta de control social para la salvaguarda del medio ambiente ha sido objeto de largas discusiones doctrinales que se han acentuado, en particular, por problemas como la identidad y delimitación del bien jurídico protegido y sus técnicas legislativas de tipificación, los modelos de imputación, el recurso a la ley penal en blanco y, junto con lo anterior, la accesoriedad administrativa del Derecho Penal medioambiental.

dispuestas por la SMA. (vii) Constituyan una negativa a entregar información relevante en los casos que la ley autoriza a la SMA para exigirla. (viii) Constituyan persistente reiteración de una misma infracción calificada como leve. (ix) Se ejecuten al interior de áreas silvestres protegidas del Estado, sin autorización. Finalmente, son infracciones leves los hechos, actos u omisiones que contravengan cualquier precepto o medida obligatorios y que no constituyan infracción gravísima o grave, de acuerdo a lo señalado precedentemente.

43 SUPERINTENDENCIA DEL MEDIO AMBIENTE. Bases Metodológicas para la determinación de sanciones ambientales. Santiago, 29 de octubre de 2015. Pp.17 y ss. 
2) El Derecho Penal no puede ser considerado como prima o única ratio para la solución de problemas sociales cuando existen herramientas de control proporcionadas por otras ramas del ordenamiento jurídico que permiten enfrentar los mismos conflictos a un menor costo. Sin embargo, la relevancia del bien jurídico medio ambiente, de los ecosistemas y, en definitiva, de los distintos recursos naturales que lo integran, su incidencia o conexión con la calidad de vida y salud de las personas, así como la gravedad de ciertas conductas que atentan contra los mismos, aconsejan -desde nuestra perspectiva- la inclusión de esta rama del ordenamiento jurídico como herramienta de protección. Ello debe hacerse, en todo caso, a conciencia, de manera que se respete en todo momento el principio de ultima ratio, es decir, reservándose el reproche penal para aquellas conductas atentatorias contra el medio ambiente realmente graves, evitando su manipulación como respuesta a situaciones concretas y particulares que, aun cuando generen malestar social y la presión del público, pueden y deben ser debidamente abordadas por el Derecho Administrativo, que constituye el primer y principal instrumento llamado a resolverlas y, en su caso, a sancionarlas.

3) La protección penal de los bienes jurídicos colectivos, entre los que se encuentra el medio ambiente, suele articularse mediante la técnica de los tipos de peligro, pues aunque los tipos de lesión han sido -tradicionalmente- la base de los sistemas penales, el desarrollo de las sociedades modernas y la aparición de la idea de "sociedad de riesgos", han fomentado el adelantamiento de la intervención penal. Con el objeto de justificar este adelantamiento, se ha sostenido la ineficacia de las fórmulas de lesión para la protección de los bienes jurídico-penales colectivos, porque se actuaría ex post, es decir, cuando el bien jurídico hubiere resultado afectado. Sin embargo, y a pesar de su validez, este argumento no pondera adecuadamente -en nuestra opinión- el efecto preventivo que conlleva, en sí misma, la incorporación del Derecho Penal como herramienta de protección del medio ambiente, de manera que aun cuando se recurra -como técnica legislativa- a los delitos de lesión, la sola amenaza de la intervención penal en caso de verificarse conductas atentatorias contra el medio ambiente podría resultar suficiente para inhibir a los potenciales agentes. Por otro lado, ligado al establecimiento del delito ecológico como delito de peligro, surge una cuestión y dificultad adicional, consistente en definición de la tipificación como delitos de peligro concreto, de peligro abstracto $\mathrm{y}$, más recientemente, de peligro hipotético. Si la opción legislativa es adelantar la intervención penal para otorgar mayor eficacia a la prevención de los atentados contra el medio ambiente, recurrir a las fórmulas de peligro concreto puede resultar inadecuado, en la medida que a través de esta técnica la lesión del bien jurídico aparece muy cercana y la verificación ex ante de peligro resulta difícilmente constatable. Pero, por otro lado, la articulación de la protección de los bienes jurídicos colectivos, como el medio ambiente, a través de los tipos de peligro abstracto supone una flexibilización -a nuestro juicio- poco adecuada de las garantías del Derecho Penal e infringe el principio de intervención mínima, básicamente, por dos razones. La primera de ellas es que la mera presunción de peligrosidad de la conducta no satisface los requerimientos mínimos de lesividad material que deben verificarse en la acción para ser merecedora del reproche que 
supone per se la imposición de una pena; $\mathrm{y}$, la segunda, es que la formulación típica y adelantada imposibilita la visualización del bien jurídico protegido $\mathrm{y}$, por consiguiente, los efectos limitadores de aquél en relación con la intervención punitiva del Estado.

4) La tipificación de los delitos ecológicos también suele configurarse mediante la técnica de leyes penales en blanco, es decir, mediante normas que no describen la conducta en su totalidad, sino que reenvían a otras disposiciones en las que se complementa el supuesto de hecho que, en el caso del medio ambiente, son generalmente de índole administrativa. Esta fórmula no ha sido para nada pacífica. Las principales críticas se relacionan con el quebrantamiento del principio de legalidad penal. Sin embargo, el sector mayoritario de la doctrina admite la presencia de las leyes penales en blanco, pues se reconoce que, en determinadas materias, se trata de un mal necesario que, entre otras ventajas, elimina la posibilidad de la sanción múltiple en perjuicio del principio "ne bis in ídem". ${ }^{44}$ En nuestra opinión, las normas penales en blanco no afectan el principio de legalidad, a menos que la norma extrapenal, integrante de la norma punitiva, describa la prohibición de manera difusa y poco concreta, afectando la certeza de la ley, circunstancia que puede ocurrir incluso en leyes que no recurran a la técnica del reenvío.

5) En Chile, hasta ahora, no se ha presentado una discusión seria ni se ha abordado con real interés la tutela penal del medio ambiente. Ello se evidencia en la gran cantidad de Proyectos de Ley vigentes y descoordinados sobre la materia, en la ligereza de gran parte de las propuestas que actualmente se encuentran en el Congreso Nacional y, por supuesto, en el estado de tramitación de las mismas. Con todo, para el evento que en alguna instancia, se llegue al convencimiento efectivo -y no con fines puramente electorales- de sancionar criminalmente los atentados graves contra el medio ambiente, debe tenerse en consideración -en primer lugar- que se trata de un bien común porque pertenece a todos, que responde a necesidades de subsistencia del conjunto de los miembros de la sociedad, incluso a generaciones venideras y que desde una perspectiva amplia- se encuentra conformado por diversos elementos, tanto naturales como artificiales. Ahora bien, los mecanismos para su tipificación, así como la determinación de los recursos que formarán o no parte del bien jurídico tutelado deben depender, en nuestra opinión, de su relevancia para el país y de las necesidades concretas que se presenten, aunque -en cualquier caso- para una adecuada regulación, el tratamiento jurídico habrá de ser consistente con sus especiales características, es decir, con el carácter colectivo del mismo y los intereses difusos involucrados.

6) En el ámbito de la ciencia jurídico penal, tradicionalmente se ha esgrimido la máxima conforme a la cual se niega responsabilidad penal a las personas jurídicas a partir del principio Societas Delinquere Non Potest. Este aforismo que dominó por muchos años en la doctrina penal tradicional y, consecuentemente, marcó la pauta en

44 TIEDEMANN, K. El Derecho Penal del Ambiente. Cuestiones Dogmáticas Novedosas, en Derecho penal económico y de la empresa. Lima, 1993. Ed. San Marcos. Pp. 260. 
los sistemas jurídicos de Europa Continental y de América Latina, ha ido modificándose lenta y progresivamente. La introducción de la responsabilidad penal de las personas jurídicas -aunque con distintos grados y matices- es una de las novedades más trascendentales en el ámbito jurídico-criminal de los últimos años, tanto en España como en Chile, porque afecta los principios básicos y estructurales de los respectivos sistemas legales. En ambos casos, aludiéndose a factores externos a las realidades nacionales, los legisladores han hecho vista gorda de la legislación ordinaria y vigente en dichos países. ${ }^{45}$

La realidad criminológica, generada -según la doctrina- a partir de la idea de sociedad de riesgos contemporánea, dinámica y globalizada, ha llevado a la tendencia -con gran presión internacional- de sustituir el concepto de delito realizado por una persona física, contra una víctima y lesionando bienes jurídicos fundamentalmente individuales, por una noción que comprende comportamientos complejos, cometidos por varias personas que pertenecen a una organización, en el seno de ella o bajo su amparo y que se caracterizan, en muchas ocasiones, por lesionar o poner en peligro los denominados bienes jurídicos colectivos o supraindividuales. Debido a lo anterior, se argumenta que la determinación de la responsabilidad penal individual, en este nuevo escenario, puede resultar compleja, pues en muchos casos el tipo objetivo y el tipo subjetivo no concurre en una misma persona, sino que se divide en conductas parciales de distintos sujetos, pertenecientes a una misma corporación (aunque geográficamente pueden encontrarse dispersos) y que sumadas conducen a la realización del hecho punible.

7) La imposibilidad o dificultad que puede surgir para determinar las responsabilidades penales de las personas físicas que actúan en la esfera de un ente colectivo no resulta, a nuestro juicio, un argumento suficiente para justificar la imposición de sanciones criminales a las personas jurídicas, con el -consecuentequebrantamiento de los principios que deben regir en materia penal y cuya configuración en este ámbito ha debido adaptarse significativamente desde el punto de vista dogmático, en los países que han optado por seguir la tendencia internacional de incluir como sujeto del Derecho Penal a los entes morales. Es más, la utilización de esta herramienta de control social puede resultar contraproducente al fin pretendido, en la medida que puede contribuir a la impunidad de aquellas personas naturales que efectivamente hubieren incurrido en las conductas ilícitas contra

\footnotetext{
${ }^{45}$ Así, por ejemplo, en España -en 2010- se introdujo la responsabilidad criminal de los entes morales con indiferencia de la definición legal de delito recogida en el art. 10 del Código Penal y del principio de responsabilidad subjetiva recogido en el art. 5 del mismo cuerpo normativo. Algo similar ocurrió en Chile, cuando -a fin de cumplir con los requerimientos de la OCDE- se incorporó, en 2009, la responsabilidad penal de las personas jurídicas, sin considerar lo dispuesto en el art. 58 del Código Procesal Penal y en el art. 39 del Código de Procedimiento Penal, que establecen que la responsabilidad penal sólo puede hacerse efectiva en las personas naturales y que por las personas jurídicas responden los que hubieren intervenido en el acto punible.
} 
aquellos bienes jurídicos que se han estimado como relevantes. Si a ello, se suma la banalización del instrumento jurídico penal que puede observarse, producto de la expansión de esta rama del ordenamiento jurídico, el panorama es poco alentador en relación con la pérdida de eficacia que puede traer aparejada y especialmente grave si se trata de proteger eficazmente bienes jurídicos relevantes como ocurre con el medio ambiente. Por otra parte y a pesar que -para justificar la intervención penal- se esgrime con gran frecuencia la insuficiencia del Derecho Administrativo para enfrentar las conductas ilícitas llevadas a cabo bajo el amparo de los entes colectivos, no ha sido posible encontrar evidencia empírica en cuanto a que la potestad sancionadora de la Administración resulte escasa para hacer frente a defectos organizativos de las empresas.

8) Tanto en España como en Chile, la responsabilidad penal de la persona jurídica aparece como corolario de la responsabilidad penal de una persona física, pues en ambos casos se concibe como un efecto de la conducta "humana" de sus representantes, administradores o trabajadores, es decir, se construye sobre el supuesto de la comisión de un delito por una determinada persona natural (condición de punibilidad). También, en ambos sistemas, la criminalización de las empresas intenta acercarse al injusto propio a través del incumplimiento de deberes de control y supervisión. Sin embargo, este modelo no solo se aleja de la realidad, sino que supone admitir que el deber de control reviste una entidad suficiente como para considerarlo un bien jurídico penal.

9) La consideración de las personas jurídicas como sujetos de Derecho Penal constituye, en realidad, una instrumentalización del sistema para influir sobre las decisiones que toman las personas físicas que las controlan o administran, pues directa o indirectamente- se asume que sólo las personas naturales pueden delinquir. Esta decisión legislativa, resulta delicada y debe ser debidamente ponderada, por varias razones. La primera es que la medida de sancionar penalmente a las personas jurídicas por la existencia de un defecto de organización, a pesar de respetar en mayor medida el principio de culpabilidad, afecta -sin lugar a dudas- el principio de subsidiariedad, porque en este caso no existiría lesión alguna a un bien jurídico penal (de las características y entidad a que se requiere) y, eventualmente, el principio de proporcionalidad, dado que -siendo el injusto del ente colectivo siempre el mismo (organización defectuosa)- el castigo a la empresa, en principio, no podría variar dependiendo de la gravedad de la conducta ilícita de las personas físicas. Por otro lado, si las sanciones que se imponen a las personas jurídicas conforme a la legislación española y chilena son consideradas como genuinas sanciones penales, se requiere asumir -entre otras cosas- una modificación no menor del concepto de pena y del significado e implicancias que ha tenido tradicionalmente esta rama del ordenamiento jurídico, porque -con la instrumentalización antes señalada- el Derecho Penal puede llegar a transformarse en un derecho de bagatelas y la sanción penal puede perder -en gran medida- su capacidad comunicativa y, por ende, su finalidad preventiva.

10) Instar por sancionar criminalmente a las empresas por ilícitos medioambientales puede resultar políticamente conveniente y llevarlo a cabo puede 
parecer lo adecuado si se considera exclusivamente el hecho que los mayores atentados se materializan en el ámbito empresarial, pero se requiere de un análisis concienzudo y profundo de las consecuencias que, para el Derecho Penal y para la protección del mismo bien jurídico medio ambiente, puede acarrear una decisión apresurada e impulsada por motivos equivocados. La responsabilidad penal de las empresas no se condice con la teoría del delito y trasgrede varios de los principios estructurales del derecho penal, al punto que esta herramienta punitiva-que reviste de una significancia trascendental para el orden social- puede verse reducida a un medio de presión (e incluso coacción) para las personas físicas que controlan o administran a las entidades colectivas, alterando el concepto de pena y el reproche asociado a la misma, circunstancia que podría redundar en una rebaja considerable de su estándar de aplicación, así como en su credibilidad y buen funcionamiento, afectando -al menos potencialmente- la eficacia preventiva que tradicionalmente se ha asociado a la misma. Estos efectos indeseados de una tendencia expansiva y criminalizadora, materializada en la responsabilidad penal de las personas jurídicas, son de especial relevancia en materia medio ambiental, en la que -precisamente- la disuasión juega un rol fundamental.

11) No obstante que la potestad administrativa sancionatoria es consecuente con los fines preventivos y disuasorios de toda sanción ${ }^{46}$, los estándares que se utilizan para su aplicación son más laxos que en materia penal. Así, por ejemplo, a pesar que en el ámbito administrativo no se discute la exigencia de antecedentes probatorios que sustenten la existencia de una infracción, el nivel de persuasión y convencimiento que se requiere para tomar la decisión de imponer una sanción al eventual infractor es de menor intensidad que el requerido para el ámbito penal. ${ }^{47}$ Por ello, es posible prever que en caso de materializarse conductas atentatorias contra el medio ambiente, se sancionará mucho menos en el ámbito penal que en un proceso administrativo, en el que estándar probatorio es más flexible y en el que, por ende, la aplicación de las reglas de conductas resulta más intensa. Asimismo, pueden apreciarse otras diferencias relevantes entre ambos sistemas jurídicos, que permiten suponer una menor cantidad de sanciones de índole criminal en caso de ilícitos ambientales. Entre ellas destaca, el principio de culpabilidad y su alcance en las dos ramas del ius puniendi Estatal. En efecto, mientras en el Derecho Penal el principio de culpabilidad constituye un límite al poder punitivo o a la pena, entendemos que en el Derecho Administrativo la culpabilidad es, básicamente, funcional a la disuasión de conductas incorrectas. Y es por ello que, a pesar que la culpabilidad define la imputación en la esfera penal, en el ámbito administrativo, la culpabilidad corresponde a una parte que

\footnotetext{
${ }^{46} \mathrm{Su}$ finalidad es hacer coercible, aplicable, ejecutable un cierto o determinado estándar de comportamiento, aportando razones para la acción futura de aquellos a quienes afectan los deberes de ese estándar. LETELIER WARTENBERG, R. Garantías penales y sanciones administrativas. Polít. Crim. Vol. 12, No 24 (Diciembre 2017), Art. 1. Pp. 637.

${ }^{47}$ LETELIER WARTENBERG, R. Garantías penales y sanciones administrativas. Op. Cit. Pp. 641.
} 
podría denominarse "accidental", toda vez que en este último, más que determinar si la infracción se comete con dolo o culpa, lo que interesa comprobar es si existe responsabilidad en la conducta que vulnera el ordenamiento jurídico y si existen circunstancias de fuerza mayor o caso fortuito que permitan, al agente, eximirse de la misma. ${ }^{48}$ Así, en caso de ilícitos contra el medio ambiente, la aplicación de un principio de culpabilidad que podemos llamar "atenuado" en un proceso administrativo sancionador, acarreará -a nuestro juicio- dos efectos relevantes. El primero, una mayor eficacia preventiva, pues -la rebaja en el estándar de culpa necesario para la imposición de una sanción- debiese constituir un incentivo para instaurar una mayor y mejor supervisión por parte de las personas físicas que controlan y administran al ente moral. Y, el segundo, una mayor cantidad de conductas sancionadas que en el ámbito penal, debido a la menor exigencia en cuanto al grado de culpabilidad y, consecuentemente, al menor estándar de prueba requerido.

De otro lado, no podemos dejar de mencionar el hecho que tanto la legislación española como la chilena, consideran como elemento gravitante de la responsabilidad penal de las empresas, el establecimiento de los denominados programas de cumplimiento. Esta circunstancia agrega un elemento más que se debe considerar a la hora de analizar la conveniencia de establecer esta clase de responsabilidad en materia de medio ambiente, pues -aun cuando la intención sea incentivar la autorregulación por parte de las compañías- bastará que las personas jurídicas instauren un catálogo de conductas prohibidas, formal o de simple maquillaje, pero dotado de las características y órganos legales requeridos, para que se dificulte enormemente la labor de investigación y configuración del delito, así como la aplicación de una sanción, pues después de todo deberá acreditarse que el programa de cumplimiento no era idóneo para prevenir delitos de esta naturaleza.

A lo dicho anteriormente, se suma que -al menos en Chile- la jurisprudencia más reciente de los tribunales de justicia ha determinado que las garantías penales que asisten al sujeto no son extrapolables automáticamente a los procesos sancionatorios administrativos ${ }^{49}$, sino que en estos últimos deben entenderse atenuadas, es decir, son mucho menos rigurosas. Ello podría redundar en que las sanciones de los procesos administrativos sean más y más rápidas, circunstancia que parece más acorde con la

\footnotetext{
48 BERMÚdEZ SOTO, J. Derecho Administrativo General. Santiago, 2014. Ed. Legal Publishing. Pp. 288.

${ }^{49}$ La Corte Suprema ha resuelto "dicha carencia legislativa y el común origen de ambas sanciones no autorizan para aplicar de manera automática las normas y principios propios del derecho penal al derecho administrativo sancionador, sino que tal aplicación debe efectuarse dentro de los márgenes del procedimiento administrativo en general y del sancionatorio en particular, sin perder de vista el contexto que tuvo en vista el legislador para optar por una u otra sanción." Y todo ello "para garantizar, de un modo más eficaz, los intereses sociales que en dichos ámbitos se encuentran en juego, lo que en caso alguno implica afirmar que, por ello, la Administración queda libre del control jurisdiccional en su obrar material y jurídico". Corte Suprema, Fisco de Chile con Dörr Zegers (2014), Rol 10792014.
} 
necesidad de proteger, con mayor eficacia, el bien jurídico medio ambiente. En este sentido, no podemos olvidar que -en caso de establecerse la responsabilidad penal de las empresas por esta clase de delitos- si se verifican conductas que atenten contra el medio ambiente, debiese preferirse la vía penal por aplicación del principio non bis in idem, con todas las dificultades probatorias que ello conlleva, arriesgándose -en cierta medida- la impunidad de la conducta o, al menos, aplazándose la sanción.

12) Desde la incorporación de la responsabilidad criminal de las corporaciones, la experiencia española ha sido muy escasa y no muestra evidencia empírica que permita analizar y/o verificar la existencia de una real justificación en cuanto a su necesariedad ni su conveniencia, derivada de la supuesta mayor eficacia de la herramienta penal en la tutela del medio ambiente. ${ }^{50}$ Lo mismo ocurre en el caso chileno, respecto de los delitos incluidos en el catálogo legal por los que se puede imputar a las personas jurídicas.

Por otro lado, de las estadísticas proporcionadas por la SMA puede colegirse que, en Chile, la gran mayoría de los agentes cumplen con la normativa ambiental y sus respectivas RCAs, porque en un porcentaje menor y cada vez menos, se inician procesos administrativos que terminan con la aplicación de sanciones. Esta circunstancia evidencia, en principio, la ausencia de ilícitos en el ámbito empresarial que -al menos por volumen- justifiquen la intervención punitiva del Estado. Adicionalmente, existen otras circunstancias que permiten sostener -por ahora- la inconveniencia de criminalizar las conductas empresariales en materia medio ambiental. Entre ellas: (a) las penas más relevantes de la legislación penal chilena son similares a las sanciones que considera la normativa de índole administrativa ${ }^{51}$ y nada obsta a que, aquellas penas no contempladas en esta última, puedan ser incorporadas en el futuro, en caso de estimarse necesario; (b) para la determinación de las sanciones administrativas se utiliza una metodología diseñada conforme a estándares internacionales, basada - precisamente- en la finalidad disuasiva y preventiva que debe caracterizarlas; y (c) existen elementos disuasorios en el ámbito administrativo

\footnotetext{
${ }^{50}$ A marzo de 2017, solo se conocen 8 sentencias del Tribunal Supremo español en relación con la responsabilidad penal de las personas jurídicas. Solo una de ellas (Roj STS 2616/2016) se relaciona con los delitos contra recursos naturales y medio ambiente. En dicho caso, se condenó a la persona física aun cuando esta última intentó escudarse en la responsabilidad penal de las personas jurídicas, porque -en opinión del Tribunal- a la fecha de la comisión del delito, no había entrado en vigor la reforma al Código Penal (art. 31 bis).

${ }^{51}$ Las sanciones administrativas son (i) revocación de RCA (cuyos efectos son equivalentes a la disolución de la persona jurídica, pues impide totalmente la operación de las actividades desarrolladas por la empresa); (ii) clausura temporal o permanente; (iii) multas de hasta 10.000 UTA; (iv) amonestación escrita. Por su parte, las penas pueden ser: (i) disolución de la persona jurídica o cancelación de la personalidad jurídica; (ii) prohibición temporal o perpetua de celebrar actos y contratos con los organismos del Estado; (iii) pérdida parcial o total de beneficios fiscales o prohibición absoluta de recepción de los mismos por un período determinado; (iv) multa a beneficio fiscal, hasta por 20.000 UTM; y (v) penas accesorias, como la publicación de la sentencia condenatoria.
} 
de gran relevancia, a saber: (i) las multas, que constituyen la sanción por antonomasia en ambos sistemas cuando se trata de entidades colectivas ${ }^{52}$, son considerablemente más altas en el sistema administrativo sancionatorio que en el penal; y (ii) a diferencia de lo que ocurre en el orden penal, en el ámbito administrativo, las personas naturales que representan legalmente o que actúen en nombre de la persona jurídica son subsidiariamente responsables del pago de las multas que se impongan a esta esta última.

De este modo, en nuestra opinión y dada la regulación existente en Chile, resulta poco sensato inclinarse por la criminalización de las empresas, bajo el pretexto del mayor efecto disuasivo de la protección penal del medio ambiente, cuando con ello pareciera- que se apunta en sentido contrario, de manera que -en lugar de responsabilizar a las empresas por ilícitos penales contra el medio ambiente, con el consecuente desgaste del Derecho Penal así como de los principios que le inspiranserá más coherente con el objetivo de lograr una protección más eficaz y eficiente de ese bien jurídico, seguir trabajando y perfeccionando un Derecho Administrativo de prevención del ilícito en el contexto empresarial, incentivando desde este ámbito el desarrollo de una autorregulación de las compañías más riesgosas, pues se obtendrá muy probablemente- una mayor prevención de conductas atentatorias contra el medio ambiente y una mayor cantidad de sanciones para las acciones $u$ omisiones típicas que en el sistema penal.

\section{Bibliografía}

Abanto Vásquez, M. (2010) Responsabilidad penal de los entes colectivos: una revisión crítica de las soluciones penales. Revista penal, ISSN 1138-9168, No 26, 2010.

Beck, U. (1994) La reinversión de la política: hacia una teoría de la modernización reflexiva (versión española de J. Alborés), en Modernización reflexiva. Política, tradición y estética en el orden social moderno. Madrid. Alianza Editorial.

Bermúdez Soto, J. (2014) Derecho Administrativo General. Santiago. Ed. Legal Publishing.

Blanco Lozano, C. (2003) Derecho Penal, Parte General. Madrid, 2003. Ed. La Ley.

Boldova Pasamar, M. (2013) La introducción de la responsabilidad penal de las personas jurídicas en la legislación española. Estudios Penales y Criminológicos Vol. XXXIII. Universidad de Santiago de Compostela/ Servicio de Publicaciones e Intercambio Científico.

Brandariz Garcia, J.A. (2011) La problemática de las normas penales en blanco, en Faraldo Cabana, P. (Dir.) / Puente Aba, L.M. (Coord.), Ordenación del territorio, patrimonio

\footnotetext{
${ }^{52}$ En materia penal, las multas pueden alcanzar un máximo de USD 1,5 millones; y en el ámbito administrativo, pueden llegar hasta USD 9 millones (valores aproximados, a septiembre de 2017).
} 
histórico y medio ambiente en el Código penal y la legislación especial. Valencia. Tirant lo Blanch.

Cerezo Mir, J. (2002) Los delitos de peligro abstracto en el ámbito del Derecho Penal del

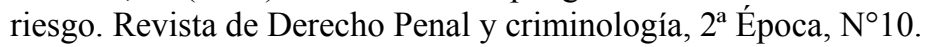

De La Cuesta Arzamendi, J. (1999) Cuestiones dogmáticas relativas al delito de contaminación ambiental. Revista Penal, 4.

Díaz Ripolles, J.L. (2012) La responsabilidad penal de las personas jurídicas. Regulación española. Indret: Revista para el Análisis del Derecho, ISSN-e 1698-739X, Nº 1.

Fraga Gomez, O. (2013) Responsabilidad penal de las personas jurídicas. Los modelos de organización y gestión, "Compliance", en el proyecto de reforma del Código Penal de 2013. Cuaderno Electrónico de Estudios Jurídicos. Núm. 1, Año 2013 (Diciembre).

Gómez-Jara, C. (2006) La responsabilidad penal de las empresas en los Estados Unidos. Madrid. Editorial universitaria Ramón Areces.

Jimenez Díaz, M. (2014) Sociedad del riesgo e intervención penal. Revista Electrónica de Ciencia Penal y Criminología, núm. 16-08.

Letelier Wartenberg, R. (2017) Garantías penales y sanciones administrativas. Polít. Crim. Vol. $12, \mathrm{~N}^{\mathrm{o}} 24$ (Diciembre), Art. 1.

Matus Acuña, J.P., Orellana Cruz, M., Castillo Sánchez, M. y RAMÍREZ Guzmán, M. (2003). Análisis dogmático del Derecho Penal ambiental chileno, a la luz del derecho comparado y las obligaciones contraídas por Chile en el ámbito del derecho internacional: conclusiones y propuesta legislativa fundada para una nueva protección penal del medio ambiente en Chile. Ius et Praxis, 9(2), 11-57. (On line) Disponible en https://dx.doi.org/10.4067/S071800122003000200002 (Visitado julio de 2017)

Molina Fernández, F. (2016) Societas peccare non potest...nec delinquere, en Estudios de Derecho Penal, Homenaje al profesor Miguel Bajo, Madrid. Ed. Centro de Estudios Ramón Areces.

Morillas Cueva, L. (2011) La cuestión de la responsabilidad penal de las personas jurídicas. Anales de Derecho. Número 29.

Muñoz Conde, F. (2015) Derecho Penal, Parte Especial. Valencia. 20 a Ed. Tirant lo Blanch.

Muñoz Conde, F. y García Arán, M. (2015) Derecho Penal, Parte General. Valencia, Ed. Tirant lo Blanch.

Muñoz Conde, F., López Peregrín, C. y García Alvarez, P. (2015) Manual de Derecho Penal medioambiental. $2^{\text {a }}$ Edición, Valencia. Ed. Tirant lo Blanch.

Nieto Martín, A. (2008) La responsabilidad penal de las personas jurídicas: un modelo legislativo. Madrid. Ed. Iustel.

Ossandón Widow, M. (2003) Eficiencia del Derecho Penal. El caso de los delitos contra el medio ambiente. Revista de Derecho de la Pontificia Universidad Católica de Valparaíso, XXIV (Valparaíso, Chile)

Pariona Arana, R. (2005) Aproximaciones al Derecho penal económico. Del nacimiento de un nuevo Derecho penal a una aproximación crítica, en L. Reyna Alfaro (coord.), Nuevas tendencias del Derecho penal económico y de la empresa. Lima. Ara Editores.

Pinedo Hidalgo, P. ¿Vulneración del non bis in idem mediante la aplicación de consecuencias accesorias a las personas jurídicas?. (On line) Disponible en http://perso.unifr.ch/derechopenal/assets/files/articulos/a_20111108_02.pdf 
Ramirez Torrado, M. (2013) El non bis in idem en el ámbito administrativo sancionador. Revista de Derecho No 40, Barranquilla.

Rodríguez Mourullo, G. (2013) El fundamento de la responsabilidad penal de las personas jurídicas según la Circular 1/2011 de la Fiscalía General del Estado, en Libro Homenaje al Profesor Luis Rodríguez Ramos (Coord. Álvarez García, F., Cobos Gómez de Linares, M., Gómez Pavón, P., Manjón-Cabeza Olmeda A. y Martínez Guerra, A.) Valencia, Ed. Tirant lo Blanch.

Serrano Tárraga, M., Serrano Mállo, A. y Vázquez González, C. (2013) Tutela penal ambiental. Madrid, $2^{\mathrm{a}}$ Ed. Dykinson.

Superintendecia Del Medio Ambiente (2016) Cuenta Pública 2015.

Superintendencia Del Medio Ambiente. (2015) Bases Metodológicas para la determinación de sanciones ambientales. Santiago, 29 de octubre de 2015.

Szczaranski Cerda, C. (2011) Un asunto criminal contemporáneo. Rol de las empresas, responsabilidad penal de las personas jurídicas y corrupción. Santiago. Ed. Jurídica de Chile.

Tiedemann, K. (1993) El Derecho Penal del Ambiente. Cuestiones Dogmáticas Novedosas, en Derecho penal económico y de la empresa. Lima. Ed. San Marcos.

Van Weezel, A. (2010) Contra la responsabilidad de las personas jurídicas. Polít. crim. Vol. 5, No 9 (Julio 2010), Art. 3.

Vercher Noguera, A. (2003) Evolución jurisprudencial del delito contra el medio ambiente. Revista Jurídica de Castilla y León. No 1, septiembre de 2003.

Zugaldia Espinar, J.M. (2010) Aproximación teórica y práctica al sistema de responsabilidad criminal de las personas jurídicas en el Derecho Penal español. Centro de Investigación Interdisciplinaria en Derecho Penal Económico. (On line) http://www.ciidpe.com.ar/area1/Z\%20Espinar.pdf. (Visitado julio de 2017). 